\title{
Supplemental methionine, choline, or taurine alter in vitro gene network expression of polymorphonuclear leukocytes from neonatal Holstein calves
}

\author{
M. K. Abdelmegeid, ${ }^{*} †$ M. Vailati-Riboni, ${ }^{*}$ A. Alharthi, ${ }^{*}$ F. Batistel, ${ }^{*}$ and J. J. Loor*1 \\ *Mammalian NutriPhysioGenomics, Department of Animal Sciences and Division of Nutritional Sciences, University of Illinois, Urbana 61801 \\ †Department of Animal Medicine, Faculty of Veterinary Medicine, Kafrelsheikh University, Kafrelsheikh 33516, Egypt
}

\begin{abstract}
Isolated PMNL from neonatal calves were used to evaluate the effect of Met, choline, and taurine supplementation on mRNA expression of genes related to the Met cycle and innate immunity. Five neonatal Holstein calves (3 wk old) were used for PMNL isolation and in vitro culture. The selected genes were related to the 1-carbon and Met cycles, cell signaling and cytokine mediators, inflammation, antimicrobial and killing mechanism associated genes, immune mediators, adhesion, and pathogen recognition. The results indicated that supplementation of Met, choline, and taurine increased homocysteine synthesis through upregulation of $S A H H$. Furthermore, the lower expression of $C X C R 1$, IL10, IL6, IRAK1, NFKB1, NR3C1, SELL, TLR4, and TNFA indicated that all treatments mitigated the inflammatory activation of blood PMNL. As indicated by the modulation of GCLC and GPX1, choline and taurine supplementation also affected the antioxidant system. However, data indicate that oversupplementation could alter the inflammatory and oxidative status, suggesting the existence of cytotoxicity thresholds. Overall, multiple biological processes in calf PMNL related to inflammatory response and cytoprotection against oxidative stress were affected by Met, choline, and taurine supplementation. These data underscore an important role of these compounds in pre-weaning calf nutritional management.
\end{abstract}

Key words: immunonutrition, inflammation, methyl donor, amino acid

\section{INTRODUCTION}

Although dairy producers follow advanced strategies in the management of dairy calves, 1 in 10 US dairy heifers dies before weaning due to exposure to

Received September 20, 2016.

Accepted December 10, 2016.

${ }^{1}$ Corresponding author: jloor@illinois.edu different stressors, lack of immunity, or both (Hulbert and Moisa, 2016). Immaturity of the neonatal immune system, especially, has been identified as the crucial cause of the high morbidity in newborn calves (Gruse et al., 2016). Within the first $14 \mathrm{~d}$ of life, calves are most susceptible to enteritis, diarrhea, septicemia, and pneumonia (Svensson et al., 2006; Windeyer et al., 2014). Furthermore, healthy calves are unable to reach the stability needed to complete the maturation of the innate immune response even by $90 \mathrm{~d}$ of age (Batista et al., 2015).

Maintaining host health is a vital function of the immune system, and PMNL have a fundamental role in this process. As the primary mediators of the innate immune response, thanks to their pathogen-killing capacity, they represent the first line of defense against pathogens (Paape et al., 2003; Kobayashi and DeLeo, 2009). Their recruitment is the end result of a carefully orchestrated and complex signal transduction events (Kobayashi and DeLeo, 2009; Futosi et al., 2013). For example, changes in mRNA expression, such as the activation of toll-like receptor and its target genes, stimulate synthesis of classical pro-inflammatory cytokines and chemokines (Wolowczuk et al., 2008; Jacometo et al., 2015; Chen et al., 2016).

Alongside the role of AA as building blocks for protein synthesis, dietary supplementation of AA guarantees normal immunocompetence through provision and synthesis of specific proteins (such as cytokines) and regulation of key metabolic pathways to sustain the immune response against infectious pathogens ( $\mathrm{Li}$ et al., 2007). The AA themselves have a role as cell signaling molecules (Li et al., 2007). These functions expedite the role of $\mathrm{AA}$ in the regulation of key metabolic pathways for maintenance, growth, reproduction, and immunity (Wu, 2009). Specifically to calves, Hill et al. (2008) concluded that Lys and Met are limiting AA for the newborn animal; hence, it is crucial to supplement milk protein-based milk replacers with synthetic Lys and Met to improve calf performance. The dairy NRC (2001) does not report individual AA requirements for calves, likely because such data are scarce in the 
literature. However, most commercially available milk replacers often include synthetic Met (DL-Met), Lys, and choline (CHO; choline chloride), whereas taurine (TAU) is not directly supplemented in pure form.

Rumen-protected Met is effective in providing extra metabolizable Met to balance peripartal diets of Holstein cows, improving PMNL phagocytosis capacity, migration, development, and cellular antioxidant capacity (Osorio et al., 2013; Li et al., 2016). Taurine (a Met derivative) has a key role itself in the regulation of the innate immune response by reducing tissue damage induced by bacterial infection, and it is the most abundant free AA in leukocytes, particularly in PMNL (Ekremoğlu et al., 2007; Erdamar et al., 2007; Miao et al., 2012). In addition to its anti-inflammatory and antioxidant effects, TAU possesses potent antimicrobial properties, as it can increase PMNL phagocytic ability and respiratory burst activity (Chorazy et al., 2002; Ekremoğlu et al., 2007).

We previously reported a greater postpartal PMNL activity in Met-supplemented transition cows (Osorio et al., 2013; Zhou et al., 2016b). However, to our knowledge, no literature is available to precisely describe the effects of Met, CHO, and TAU on PMNL immune function in newborn calves. We hypothesized that Met, $\mathrm{CHO}$, and TAU might partly regulate PMNL function through alterations in gene expression; hence, we determined the effect of Met, CHO, and TAU supplementation in vitro on the mRNA expression of genes related to the Met cycle, cell signaling, inflammation, antimicrobial mechanisms, immune mediators, and adhesion molecules in PMNL isolated from neonatal calves.

\section{MATERIALS AND METHODS}

\section{Animal Handling}

Animal handling and all procedures received approval from the University of Illinois Institutional Animal Care and Use Committee (protocol \#14270). Five Holstein calves (3 wk age) from the University of Illinois dairy herd were selected for PMNL isolation. Previous to blood collection, calves were fed and managed according to established standard operating procedures. First-milking colostrum was fed within $2 \mathrm{~h}$ after birth, and calves were housed in individual outdoor hutches bedded with straw. Calves were fed twice daily (0700 and $1800 \mathrm{~h}$ ) with a milk replacer (Advance Excelerate, Milk Specialties, Carpentersville, IL; $28.5 \%$ CP, $15 \%$ fat; supplemented with L-Lys and DL-Met) and had ad libitum access to a starter grain mix $(19.9 \%$ CP, $13.5 \%$ $\mathrm{NDF}$ ) at $0800 \mathrm{~h}$. Until $10 \mathrm{~d}$ of age, calves received 2.27 $\mathrm{kg}(5.0 \mathrm{lb})$ of milk replacer at each feeding, and were then switched to $2.95 \mathrm{~kg}(6.5 \mathrm{lb})$ until the time of sam- pling ( 3 wk of age). Calves did not have any recorded health problems at sampling time.

\section{Blood Sample Collection}

Blood was collected at 3 wk of age from a jugular vein at $0700 \mathrm{~h}$, before feeding, into Vacutainer tubes (BD Vacutainer, Becton Dickinson and Company, Franklin Lakes, NJ) containing $1.5 \mathrm{~mL}$ of ACD solution A (trisodium citrate, $22.0 \mathrm{~g} / \mathrm{L}$; citric acid, $8.0 \mathrm{~g} / \mathrm{L}$; and dextrose $24.5 \mathrm{~g} / \mathrm{L}$ ). Fifteen tubes were collected, for a total of 120 to $150 \mathrm{~mL}$ of blood per each calf (Jacometo et al., 2015). Tubes were inverted 10 times, immediately placed on ice, and transported to the laboratory for immediate isolation of PMNL. No more than 40 min passed from the beginning of sampling to start of isolation.

\section{PMNL Isolation and Viability Analysis}

The PMNL were isolated as previously described (Jacometo et al., 2015). The complete procedure can be found in the Supplemental Material (https://doi. org/10.3168/jds.2016-12025). Briefly, samples were centrifuged to separate the phases, then plasma, buffy coat, and approximately one-third of the red blood cells were removed and discarded. The remaining material was combined and red blood cells were lysed using deionized water at $4^{\circ} \mathrm{C}$, followed by addition of $5 \times$ PBS at $4^{\circ} \mathrm{C}$ to restore isotonicity. Cells were pelleted by centrifugation and the supernatant was discarded. The pellet was then washed with $1 \times$ PBS and a second lysis step with deionized water was performed. After repelleting, 2 subsequent washings using $1 \times$ PBS at $4^{\circ} \mathrm{C}$ were performed. The resulting neutrophil pellets from the 5 animals were then mixed to obtain a homogeneous pool, and washed again with $1 \times$ PBS. Before incubation, to assess purity and viability, an aliquot was stained with the granulocyte antibody CH138A, followed by a second antibody (phycoerythrin and propidium iodide), before the reading with a flow cytometer. The neutrophil pool had a purity greater than $90 \%$ and viability greater than $90 \%$.

\section{PMNL Incubation and Treatments}

Cells from the isolated pool of PMNL were counted using an automated cell counter (MOXI Z Mini, Orflo Technologies, Ketchum, ID) and diluted to a final concentration of $6 \times 10^{6}$ cells $/ \mathrm{mL}$ with warm $\left(37^{\circ} \mathrm{C}\right)$, Met-free incubation medium (RPMI 1640, Gibco, Thermo Fisher, Waltham, MA) and $8 \%$ of fetal bovine serum (Sigma-Aldrich, St. Louis, MO), previously heatinactivated. From the diluted pool, aliquots of $1 \mathrm{~mL}$ 
were incubated in 14-mL endotoxin-free tubes (Thermo Fisher Scientific) with a snap cap designed to allow air flow, and allocated to each experimental group. The PMNL were incubated at (1) 3 different Lys to Met ratios $(3.6: 1,2.9: 1$, or $2.4: 1)$, calculated on the basis of the concentration of Lys in the medium; (2) 3 levels of supplemental CHO $(0,400$, or $800 \mu \mathrm{g} / \mathrm{mL})$ over the basal level of CHO already in the medium $(3 \mu \mathrm{g} / \mathrm{mL}$, as choline chloride), with a Lys:Met ( $\mathbf{L}: \mathbf{M})$ of $3.6: 1$; or (3) 3 levels of supplemental TAU $(0,4$, or $8 \mu \mathrm{g} / \mathrm{mL})$, with a L:M of 3.6:1. To obtain these groups, the calculated amounts of Met (as L-Met; Sigma-Aldrich), CHO (as choline chloride; Sigma-Aldrich), and TAU (as taurine; Sigma-Aldrich) were added to test tubes from stock solutions previously prepared using the incubation medium as a diluent. Incubation lasted $4 \mathrm{~h}$ at $37^{\circ} \mathrm{C}$ in a sterile incubator, with a controlled atmospheric level of $\mathrm{CO}_{2}(5 \%)$. Tubes were gently shaken to mix and resuspend the cells every $20 \mathrm{~min}$.

\section{RNA Extraction}

After incubation, PMNL were pelleted by centrifugation $\left(10,000 \times g\right.$ at $4^{\circ} \mathrm{C}$ for $\left.2 \mathrm{~min}\right)$ and the supernatant was decanted. Total RNA was extracted using the miRNeasy kit (Qiagen, Hilden, Germany), according to manufacturer's instructions (https://www.qiagen.com/ us/resources/resourcedetail?id=632801fb-abc5-4e62-b9 54-ff51f126a34f\&lang=en). As an extra purification step, genomic DNA was removed from RNA during purification with DNase (Qiagen). The RNA concentration was measured using a NanoDrop ND-1000 spectrophotometer (NanoDrop Technologies), whereas the quality of RNA was evaluated using a 2100 Bioanalyzer (Agilent Technologies Inc., Santa Clara, CA). All samples had an RNA integrity value above 7.5 (8.7 \pm $0.6)$, with average concentration of $76.9 \pm 17.9 \mathrm{ng} / \mu \mathrm{L}$ and $260 / 230$ ratio of $1.9 \pm 0.3$.

\section{Gene Expression Analysis}

Genes selected for transcript profiling were classified based on relevant biological functions, and listed in Supplemental Table S1 (https://doi.org/10.3168/ jds.2016-12025). Synthesis of cDNA was performed using established protocols in our laboratory (Osorio et al., 2014b). The quantitative (q)PCR performed was SYBR Green-based (Quanta Biosciences, Beverly, MA), using a 7-point relative standard curve obtained from a cDNA pool of all samples diluted 1:2 for the first point, which was then serially diluted 1:4 to generate the remaining points. Complete methods (cDNA synthesis, qPCR performance, and primer design) are available in the Supplemental Material, together with primer sequences and qPCR efficiencies (Supplemental Tables S2 and S3; https://doi.org/10.3168/jds.201612025).

\section{Statistical Analysis}

After normalization with the geometric mean of the internal control genes, the averages of triplicates of the qPCR data were $\log _{2}$ transformed before statistical analysis to obtain a normal distribution. Statistical analysis was performed with SAS (v9.3, SAS Institute Inc., Cary, NC). Normalized, $\log _{2}$ transformed data were subjected to ANOVA and analyzed with PROC MIXED. The statistical model included L:M (3.6, 2.9, 2.4), supplemental CHO $(0,400,800)$, and supplemental TAU $(0,4,8)$ as fixed effects. The Kenward-Roger statement was used for computing the denominator degrees of freedom, whereas spatial power was the most appropriate covariance structure for the repeated statement. Data were considered significant at $P \leq$ 0.05 using the PDIFF statement in SAS. For ease of interpretation, the data reported in Table 1 are the $\log _{2}$ back-transformed LSM that resulted from the statistical analysis.

\section{RESULTS}

\section{Methionine Cycle and Transsulfuration Pathway}

Expression of $A L D H^{\top} 7 A 1$ and $S A H H$ was affected by all treatments (L:M, CHO, TAU; $P<0.05$; Table 1; Figures 1, 2, and 3). For both genes, greater expression was detected at a ratio of $2.9: 1$, and 400 and $4 \mu \mathrm{g} /$ $\mathrm{mL}$ for Met, CHO, and TAU, respectively. Although no significant effects of $\mathrm{CHO}$ and TAU were detected for MTR and MAT2A (Table 1), a significant effect $(P<$ $0.05)$ was detected for L:M. Compared with the other 2 ratios, the lowest expression of MTR and MAT2A was detected at a ratio of $2.9: 1$ and 2.4:1, respectively (Figure 1).

As for $A L D H 7 A 1$ and $S A H H$, a significant effect $(P<$ $0.05)$ of $\mathrm{CHO}$ and TAU was detected for the expression of GCLC. The expression of GPX1, however, was only affected by TAU $(P<0.05)$. In contrast, expression of both $G C L C$ and $G P X 1$ was greater $(P<0.05)$ at 800 and $8 \mu \mathrm{g} / \mathrm{mL}$ of $\mathrm{CHO}(G C L C)$ and TAU (GCLC, $G P X 1)$, respectively.

Expression of BHMT, CHDH, MAT1A, and PEMT was deemed undetectable (Table 1).

\section{Signaling and Cytokine Mediators}

The expression of IRAK1, NFKB1, and NR3C1 was affected by TAU $(P<0.05$; Table 1 and Figure 3$)$. 


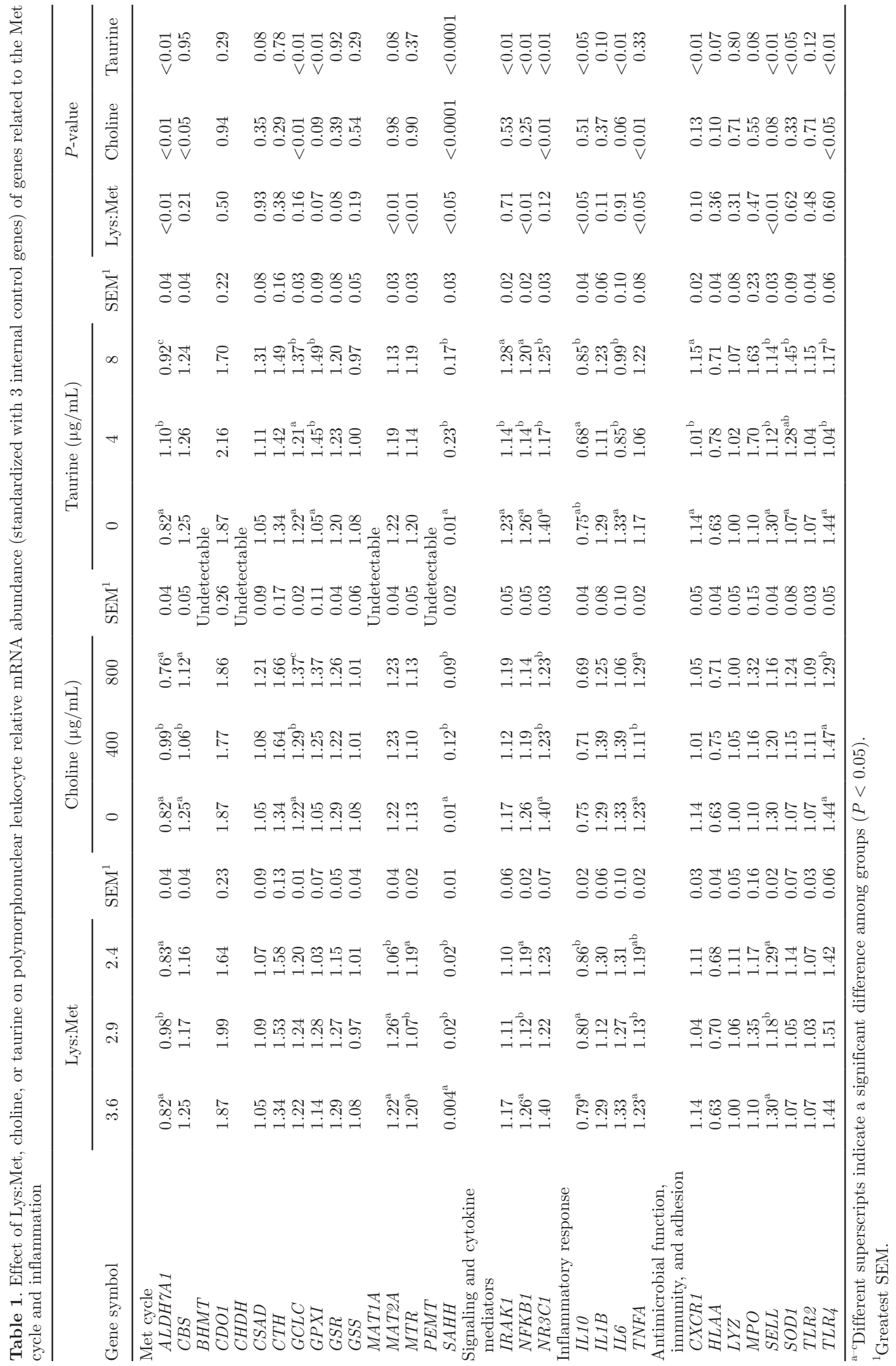



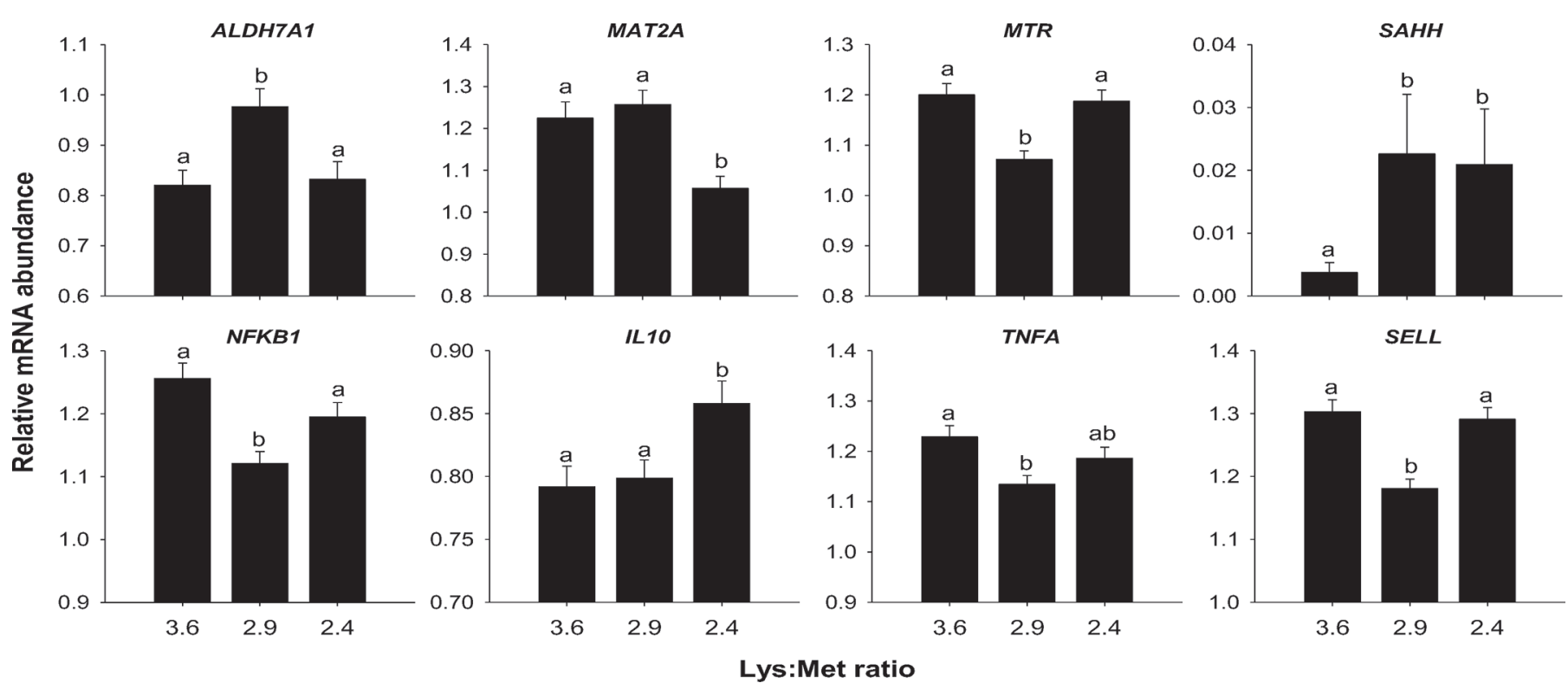

Figure 1. Effect of level of Met supplementation in vitro on relative mRNA abundance (standardized with 3 internal control genes) of significantly affected genes in PMNL isolated from neonatal Holstein calves. Error bars represent SEM of the model estimate. Bars with different letters $(\mathrm{a}, \mathrm{b})$ are significantly different $(P<0.05)$.

Compared with the other groups, TAU at $4 \mu \mathrm{g} / \mathrm{mL}$ led to lower expression of IRAK1 and NFKB1, and also a lower expression of $N R 3 C 1$ at 4 and $8 \mu \mathrm{g} / \mathrm{mL}$ of TAU (Figure 3). The ratio of L:M or $\mathrm{CHO}$ did not consistently alter the expression of these genes. In fact,
L:M only significantly affected expression of NFKB1, with a lower expression at L:M 2.9:1 compared with the other 2 groups. The $\mathrm{CHO}$ effect was significant only for NR3C1, with the greatest expression detected at $0 \mu \mathrm{g} /$ $\mathrm{mL}$ of supplemental CHO (Table 1 and Figure 2).
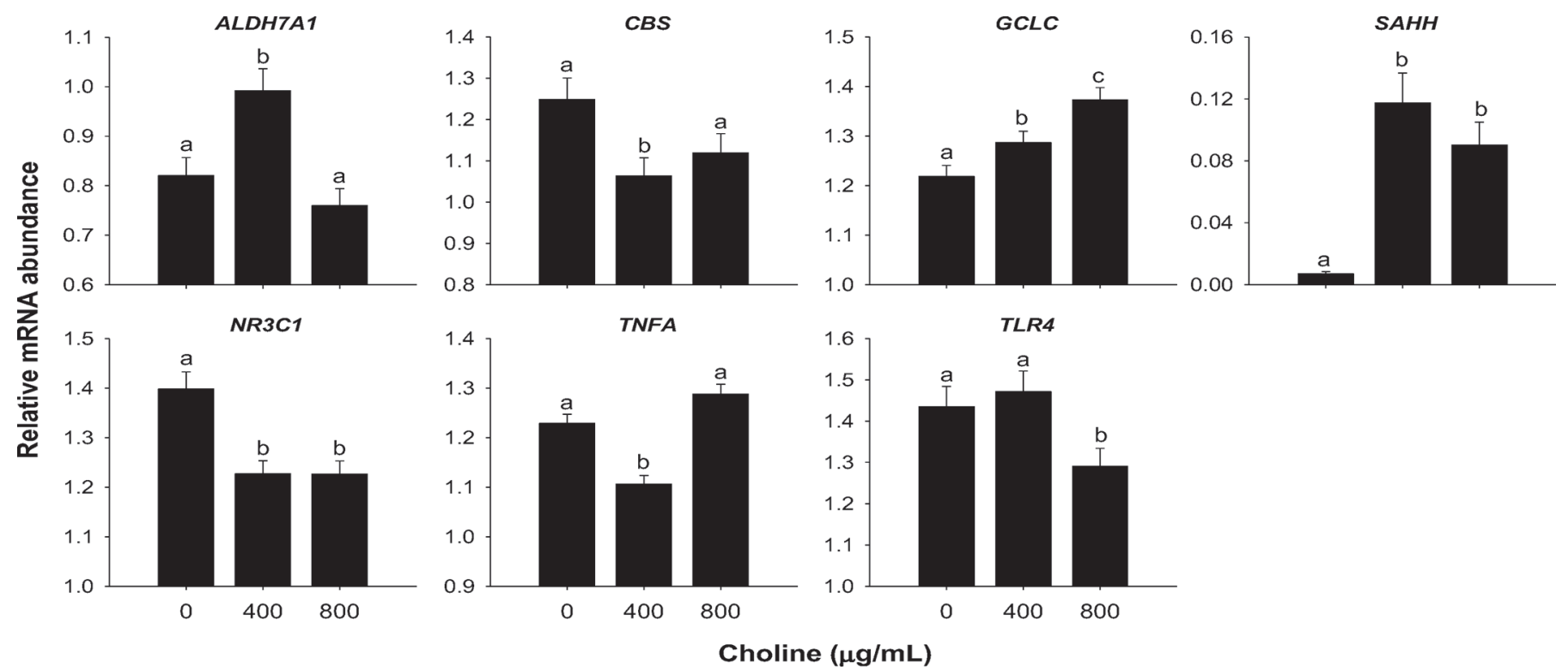

Figure 2. Effect of level of choline supplementation (at a constant Lys:Met of 3.6) in vitro on relative mRNA abundance (standardized with 3 internal control genes) of significantly affected genes in PMNL isolated from neonatal Holstein calves. Error bars represent SEM of the model estimate. Bars with different letters $(\mathrm{a}, \mathrm{b})$ are significantly different $(P<0.05)$. 


\section{Inflammatory Response}

Methionine supplementation affected the expression of both IL10 and TNFA (L:M, $P<0.05$ ), with opposite effect, as at the lowest L:M (2.4:1) IL10 was at its highest expression $(P<0.05)$, whereas TNFA reached its highest expression $(P<0.05)$ at L:M of 3.6:1. Expression of TNFA was also affected by $\mathrm{CHO}(P<0.05)$, with lowest expression at $400 \mu \mathrm{g} / \mathrm{mL}$ compared with the other 2 groups, which had similar higher expression (Table 1 and Figure 2). In contrast, the supplementation of TAU had an effect on $I L 10$ and $I L 6$, with lower level of expression at $4 \mu \mathrm{g} / \mathrm{mL}$ (Table 1 and Figure 3). No significant effect was detected for $I L 1 B$ expression (L:M, CHO, TAU, $P>0.05)$.

\section{Antimicrobial Function, Oxidative Stress, Immune Mediators, and Cellular Adhesion}

Expression of SOD1 was significant with TAU due to lower $(P<0.05)$ expression at $0 \mu \mathrm{g} / \mathrm{mL}$ compared with $8 \mu \mathrm{g} / \mathrm{mL}$ (Figure 3). Among the investigated genes involved in immune mediation and adhesion, the expression of HLAA and TLR2 was not affected $(P>$ 0.05 ) by any of the treatments (L:M, CHO, and TAU; Table 1). The effect of L:M was significant only for SELL $(P<0.05)$, with the 2.9:1 ratio causing the lowest expression level compared with the other 2 ratios. The CHO treatment instead had a significant effect only for $T L R 4(P<0.05)$, with greater expression $(P<$ $0.05)$ at 0 and $400 \mu \mathrm{g} / \mathrm{mL}$ compared with $800 \mu \mathrm{g} / \mathrm{mL}$. In contrast to the effect of L:M and CHO, TAU affected the majority of the genes in this category (CXCR1, SELL, and TLR 4; $P<0.05$; Table 1). Supplementation of TAU (either 4 or $8 \mu \mathrm{g} / \mathrm{mL}$ ) decreased $(P<0.05)$ the expression of both TLR4 and SELL compared with the unsupplemented group. Compared with the $4 \mu \mathrm{g} / \mathrm{mL}$ of TAU, both 0 and $8 \mu \mathrm{g} / \mathrm{mL}$ of TAU increased $(P<0.01)$ the expression of $C X C R 1$ (Figure 3). No effect of L:M, $\mathrm{CHO}$, and TAU was detected for the expression of $L Y Z$ and $M P O(P>0.05$; Table 1$)$.

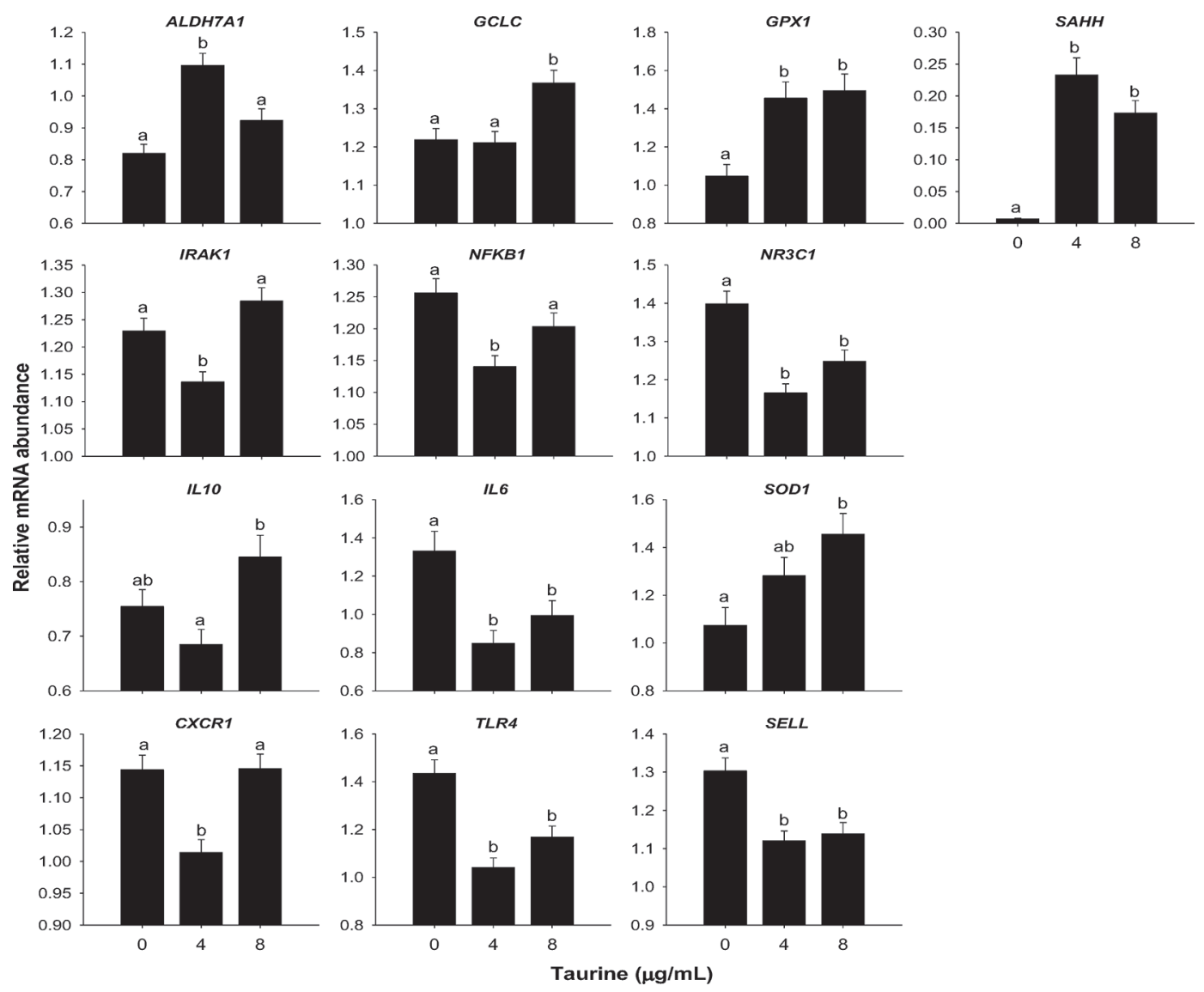

Figure 3. Effect of level of taurine supplementation (at a constant Lys:Met of 3.6) in vitro on relative mRNA abundance (standardized with 3 internal control genes) of significantly affected genes in PMNL isolated from neonatal Holstein calves. Error bars represent SEM of the model estimate. Bars with different letters $(\mathrm{a}, \mathrm{b})$ are significantly different $(P<0.05)$. 


\section{DISCUSSION}

Immunonutrition is a new scientific trend integrating nutrition and immunology research to uncover the role of nutrients on immune cell metabolism and function by integrating data at a molecular, cellular, tissue, and whole-body level (Li et al., 2007). In the present study, we explored through gene expression analysis how Met, $\mathrm{CHO}$, and TAU can individually influence the status and functionality of PMNL in neonatal Holstein calves.

\section{Methionine Effect}

Among the investigated genes involved in Met metabolism, only ALDH7A1, MTR, MAT2A, and SAHH responded to Met supplementation. The change in $S A H H$ expression implies a greater flux (i.e., the rate of turnover of molecules through the pathway) via the transmethylation pathway when additional Met was supplemented, independent of the supplementation amount. This agrees with previous in vivo data (Osorio et al., 2014a) where the greater expression of $S A H H$, a substrate-dependent enzyme, followed the increase in cellular concentration of S-adenosyl homocystein (the substrate of SAHH) elicited by supplementation of rumen-protected Met. However, when supplementing Met to reach a L:M of 2.4, the lower MAT2A expression seems to contradict the $S A H H$ response as, encoding the enzyme responsible for the entrance of Met in the cycle, its lower expression indicates a reduced, and not increased, flux through the pathway. This could potentially be interpreted as a negative feedback response without necessarily affecting enzyme activity (Schalinske, 2008).

Despite additional Met seemingly being channeled through the cycle, as indicated by $S A H H$, the $M T R$ expression indicated a different fate for the Met sulfur when the pool of available Met was greater. In fact, at a L:M of 2.9:1, the lower $M T R$ expression implies a greater flux of homocysteine through the transsulfuration pathway to generate important antioxidants such as glutathione (GSH) and TAU. This was demonstrated by previous in vivo research, as cows supplemented with rumen-protected Met had greater hepatic concentration of total and reduced GSH (Osorio et al., 2014b; Zhou et al., 2016a). Instead, when the ratio was pushed to $2.4: 1$, the excess sulfur atoms seemed to have been recycled to regenerate Met. Because no changes were detected in the expression of genes of the transsulfuration pathway, we hypothesize that due to the greater Met availability the concentration of the end product of the transsulfuration pathway (e.g., GSH and TAU) between the 2.9:1 and 2.4:1 ratios did not differ. However, in the latter case the excess Met atoms likely cycled more in the transmethylation and remethylation pathways to increase the methylation capacity of PMNL, as shown by increased genome-wide methylation in rodent models when Met availability is increased (Waterland, 2006). Furthermore, the fact that PEMT expression was undetectable indicates that these methyl groups cannot be used by PMNL to synthesize phosphatidylcholine and consequently $\mathrm{CHO}$, which are important molecules in leukocyte metabolism (Kim et al., 2007).

Of great interest is the ability of Met to modulate $A L D H^{7} 7 A 1$ expression. This gene was originally investigated for its involvement in the betaine pathway, which allows $\mathrm{CHO}$ to contribute one of its methyl groups for the remethylation of homocysteine to Met. However, $C H D H$ and BHMT, which encode enzymes for the preceding and subsequent reaction of this 3-step pathway, also were undetectable. This agrees with previous human- and bovine-specific knowledge that the betaine pathway is present only in liver and kidney, but led us to hypothesize other major roles for $A L D H^{7} 7 A 1$ in PMNL. The encoded protein is part of the aryl hydrocarbon receptor signaling cascade (Aleksunes and Klaassen, 2012), which in nonruminants influences the immune system (Stevens et al., 2009; Stockinger et al., 2011). It also has a direct role in cytoprotection against different stressors including oxidative stress (Brocker et al., 2010, 2011). Further research is required to assess the bovine-specific function of ALDH7A1 in PMNL.

Methionine has been previously linked with the regulation of the immune response in bovine monocytes and neutrophils (Osorio et al., 2013; Zhou et al., 2016a). Our results revealed a modulatory effect of Met on the expression of NFKB1, a transcription factor, TNFA and IL10, pro- and anti-inflammatory cytokines, respectively, and SELL, an adhesion molecule. Because cells were not challenged during the incubation, the lower expression of NFKB1 and TNFA [one of its inducer/ target genes (Pahl, 1999)] induced by supplementing Met to a L:M of 2.9:1 could lead to a better inflammatory status in vivo, as nuclear factor-kappa B subunit 1 is the main regulator of pro-inflammatory cytokine expression. In fact, clinically healthy adult cows with higher circulating concentrations of cytokines have been shown to underperform during the transition into lactation (Trevisi et al., 2015).

These results are consistent with the downregulation of several proinflammatory genes in bovine blood PMN after AA supplementation (Garcia et al., 2016). In the context of neonatal calves, we speculate that a better basal inflammatory status (e.g., lower pro-inflammatory signaling) would greatly help these animals that possess an underdeveloped immunity, especially in a period of high susceptibility to environmental pathogens (i.e., the postnatal stage). The expression of $S E L L$, 
however, indicated a lower functionality of PMNL, as the encoded protein is essential for PMNL migration into peripheral tissue during an immune response (Ley, 2003). Because Met supplementation increased immune function in vivo in adult cows (Osorio et al., 2013; Zhou et al., 2016a), functional tests are needed to better understand the role of its downregulation in young calves.

The modulatory effect of Met detected at a L:M of 2.9:1 seemed to fade when supplementation increased (L:M of 2.4:1). This was observed for all affected genes (NFKB1, SELL, and TNFA), but not for IL10 that encodes an anti-inflammatory cytokine and was upregulated at the higher levels of Met supplementation. The expression pattern indicated a linear effect (not statistically tested). Interleukin-10 has an inhibitory effect on chemokine and cytokine production (Bazzoni et al., 2010); however, in the current experiment these relationships were not detected, probably due to the short incubation time that did not allow for IL10 mRNA to be translated into protein and elicit an effect on expression of other cytokines. If the greater IL10 expression indicates a better inflammatory status (e.g., lower pro-inflammatory signals) in cells supplemented to achieve a ratio of 2.4:1, the upregulation of all other affected immune-related genes contradicts this hypothesis, rather suggesting the existence of an in vitro PMNL cytotoxic threshold for Met.

Overall, supplementation of Met affected the genes responsible for turnover of the Met cycle, most probably increasing the cellular availability of its sulfur-containing antioxidant derivatives (e.g., GSH and TAU). Reaching a L:M of 2.9:1 decreased the pro-inflammatory signaling of PMNL in a nonstimulated environment, suggesting a better immunological status. However, this effect was lost when supplementation was pushed to a ratio of $2.4: 1$.

\section{Choline Effect}

To our knowledge, the role of CHO supplementation on PMNL function has not been previously examined in depth. Choline, among other micronutrients, is an important source of methyl groups in the 1-carbon metabolism, which generates S-adenosyl Met, a key methyl donor to methylate DNA, RNA, and proteins (Finkelstein, 1990). Through betaine, one of its metabolites, it participates in the cycle by remethylating homocysteine (McKeever et al., 1991); however, as previously stated, this pathway is found only in mammalian liver and kidney (McKeever et al., 1991), not in PMNL. Despite the absence of the betaine pathway (confirmed by the lack of expression of $C H D H$ and $B H M T$ in our experiment), which could have elicited similar results as Met supplementation, $\mathrm{CHO}$ was able to modulate the expression of both immuno- and Met cycle-related genes.

As for Met, CHO supplementation modulated $S A H H$ expression when supplemented at both 400 and $800 \mu \mathrm{g} /$ $\mathrm{mL}$, suggesting a higher rate of homocysteine synthetized, and thus a probable greater flux of Met through the cycle despite not contributing to the initial pool of Met due to the lack of $C H D H$ and $B H M T$. Interestingly, due to a lower expression of $C B S$ encoding the first enzyme in the pathway, the use of homocysteine in the transsulfuration pathway appeared to be decreased at a supplementation rate of $400 \mu \mathrm{g} / \mathrm{mL}$ of $\mathrm{CHO}$. This response might be detrimental for PMNL due to the possible excessive accumulation of homocysteine, which becomes toxic at high concentrations and causes unwanted activation of the immune system (Boldyrev et al., 2013).

The greater expression of $G C L C$ by $\mathrm{CHO}$ supplementation ( 0 vs. $400 \mu \mathrm{g} / \mathrm{mL}$ ) indicated a greater synthesis of GSH, despite the fact that channeling of homocysteine (the sulfur carrier for GSH synthesis) to the transsulfuration pathway seemed to have been reduced. Thus, despite the fact that supplementing CHO at 400 $\mu \mathrm{g} / \mathrm{mL}$ seemed to reduce the availability of substrates for GSH synthesis, it appeared to improve the antioxidant status of PMNL. The downregulation of NR3C1 and TNFA supports this hypothesis, excluding the possibility that the upregulation of GSH synthesis might be due to an inflammatory status (which accompanies oxidative stress) in response to the greater availability of $\mathrm{CHO}(400 \mu \mathrm{g} / \mathrm{mL})$. Instead, it mimics the response detected with Met supplementation, underscoring how CHO supplementation might also improve the inflammatory status of neonatal calves.

The $400 \mu \mathrm{g} / \mathrm{mL}$ of $\mathrm{CHO}$ upregulated the expression of $A L D H{ }^{\prime} A 1$, further supporting the need for additional data on the function of this gene in PMNL. When supplementation of $\mathrm{CHO}$ doubled $(800 \mu \mathrm{g} / \mathrm{mL} \mathrm{g} / \mathrm{mL})$, the return to normal expression of $C B S$ and TNFA and the even greater expression of $G C L C$ (all supported by the still high expression of $S A H H$ ) indicated the channeling of homocysteine to the transsulfuration pathway to counteract an emerging inflammatory and oxidative stress status. These responses also underscore a possible CHO toxicity threshold in PMNL. Furthermore, as superoxide dismutases are used during the respiratory burst by leukocytes (Babior et al., 1973), the increased expression of SOD1 suggests a possible activation of PMNL, probably due to the oxidative and inflammatory stress induced by the excess of TAU. The impaired status of these cells also seemed to negatively affect their functionality as TLR 4 expression was decreased 
at $800 \mu \mathrm{g} / \mathrm{mL}$ of $\mathrm{CHO}$, suggesting a reduction in the PMNL pathogen-recognition mechanism. Clearly, functional assays are needed to validate this hypothesis.

Despite PMNL lacking the enzyme to channel CHO into the Met cycle, overall its supplementation seemed to have been able to alter turnover of the cycle, and improve the inflammatory status of the cells. Furthermore, results revealed a potential cytotoxic effect on calf PMNL when supplemental CHO reached $800 \mu \mathrm{g} /$ $\mathrm{mL}$.

\section{Taurine Effect}

Similar to Met and CHO, TAU supplementation was able to affect the expression of $S A H H$, upregulating it at both supplemental doses. This suggests that also TAU has an ability to increase production of homocysteine, and possibly increase the utilization of Met through the Met cycle. Because TAU is an end product of the transsulfuration pathway linked to the Met cycle, its ability to positively influence the expression of the upstream genes comes as a surprise. Under normal circumstances the increase in concentrations of the final products would be expected to downregulate their expression. Although a tendency was detected for $C S A D$, it is noteworthy that TAU had no effect on the expression of the genes involved in its direct synthesis (CDO1 and CSAD), indicating the potential regulation at the enzyme activity rather than transcriptional level.

When supplementing TAU at $4 \mu \mathrm{g} / \mathrm{mL}$, the lack of change in $G C L C$ expression indicated that an increase in the availability of homocysteine seemed not to have been used for GSH synthesis. It is noteworthy that the same level of supplementation elicited an upregulation of GPX1, which encodes a major enzyme in the cellular GSH antioxidant system (Nordberg and Arner, 2001). This might suggest an activation of the cytoprotective mechanisms against oxidative stress induced by TAU supplementation. However, in some human diseases, overexpression of GPX1 and other antioxidant defense enzymes is considered a good health prognosis (Tome et al., 2005). Thus, in our experiment, its upregulation might indicate a better overall status of PMNL when TAU was supplemented at $4 \mu \mathrm{g} / \mathrm{mL}$. This scenario is further supported by the anti-inflammatory effect revealed by the downregulation of the upstream receptors $C X C R 1$ and TLR4; the inflammatory signaling cascade molecules IRAK1, NFKB1, and NR3C1; and the downstream pro-inflammatory cytokine $I L 6$.

Taurine supplementation also tended to upregulate $M P O$ expression. The encoded protein is responsible for the creation of hypochlorous acid during oxidative burst by PMNL (a pathogen-killing mechanism; Hampton et al., 1998), which easily reacts with TAU to generate TAU chloramine (Schuller-Levis and Park, 2004). The anti-inflammatory effects observed with TAU in our experiment might be explained by the strong anti-inflammatory activity of TAU chloramine, which attenuates the production of proinflammatory cytokines (e.g., IL1 $\beta$, IL6, and TNFo; Wright et al., 1986; Marcinkiewicz et al., 1998; Chorazy et al., 2002). Furthermore, a similar effect of TAU was observed in mice, where its supplementation in vitro reduced the concentration of cytokines in the supernatant as well as the activity of signaling molecules (e.g., nuclear factorkappa B) of mammary epithelial cells when immune challenged (Dai et al., 2016).

When TAU supplementation was increased to $8 \mu \mathrm{g} /$ $\mathrm{mL}$, as for $\mathrm{CHO}$ and potentially Met, the evidence of a toxicity threshold emerged. If the previous beneficial higher expression of GPX1 remains unchanged compared with the $4 \mu \mathrm{g} / \mathrm{mL}$ dose, the upregulation of $G C L C$ coupled with GPX1 indicated a greater need for antioxidants to counteract a possible oxidative stress scenario. Because oxidative stress and inflammatory events are often interrelated (Sordillo and Mavangira, 2014), the restored expression of all inflammatory signaling molecules (CXCR1, IRAK1, NFKB1, NR3C1) and the activation of $I L 10$ (anti-inflammatory) support this hypothesis.

Similar to Met supplementation, the addition of TAU caused the downregulation of SELL, independent of the supplementation dose. Because TAU supplementation was previously linked to improve functionality of neutrophils, such as increased phagocytosis ability and respiratory burst (Chorazy et al., 2002; Ekremoğlu et al., 2007), the nature of its downregulation merits further studies.

Overall, a moderate TAU supplementation decreased calf PMNL pro-inflammatory signals, while increasing their antioxidant status, suggesting a better overall immunological status. As for $\mathrm{CHO}$, and potentially Met, an excessive amount (e.g., $8 \mu \mathrm{g} / \mathrm{mL}$ ) displayed signs of cytotoxicity in vitro.

\section{CONCLUSIONS}

In the pre-weaning period when calves experience high morbidity and immunologic challenges, the development of a robust innate immune system should be a priority. Overall, our data indicate that supplementation of Met, CHO, or TAU could be beneficial for the health status of neonatal calf PMNL [i.e., reduces their basal (nonchallenged) pro-inflammatory activity and improves their antioxidant balance]. However, if oversupplemented, all compounds might reach a cytotoxic threshold despite the fact that the highest concentrations tested, especially for $\mathrm{CHO}$ and TAU, are likely 
not physiological. Further research will be needed to assess the beneficial in vivo dose and the effect of the supplementation on PMNL immunological activity and function.

\section{ACKNOWLEDGMENTS}

M. K. Abdelmegeid was supported by a postdoctoral fellowship from the government of the Arab Republic of Egypt. Research was supported by Hatch funds under project ILLU-538-914, National Institute of Food and Agriculture (Washington, DC).

\section{REFERENCES}

Aleksunes, L. M., and C. D. Klaassen. 2012. Coordinated regulation of hepatic phase I and II drug-metabolizing genes and transporters using AhR-, CAR-, PXR-, PPARalpha-, and Nrf2-null mice. Drug Metab. Dispos. 40:1366-1379. https://doi.org/10.1124/ dmd.112.045112.

Babior, B. M., R. S. Kipnes, and J. T. Curnutte. 1973. Biological defense mechanisms. The production by leukocytes of superoxide, a potential bactericidal agent. J. Clin. Invest. 52:741-744. https:// doi.org/10.1172/JCI107236.

Batista, C. F., M. G. Blagitz, H. G. Bertagnon, R. C. Gomes, K. R. Santos, and A. M. Della Libera. 2015. Evolution of phagocytic function in monocytes and neutrophils blood cells of healthy calves. J. Dairy Sci. 98:8882-8888. https://doi.org/10.3168/jds.2015-9573.

Bazzoni, F., N. Tamassia, M. Rossato, and M. A. Cassatella. 2010 Understanding the molecular mechanisms of the multifaceted IL10-mediated anti-inflammatory response: Lessons from neutrophils. Eur. J. Immunol. 40:2360-2368. https://doi.org/10.1002/ eji.200940294.

Boldyrev, A., E. Bryushkova, A. Mashkina, and E. Vladychenskaya. 2013. Why is homocysteine toxic for the nervous and immune systems? Curr. Aging Sci. 6:29-36. https://doi.org/10.2174/1874609 8112059990007

Brocker, C., M. Cantore, P. Failli, and V. Vasiliou. 2011. Aldehyde dehydrogenase 7A1 (ALDH7A1) attenuates reactive aldehyde and oxidative stress induced cytotoxicity. Chem. Biol. Interact. 191:269-277. https://doi.org/10.1016/j.cbi.2011.02.016.

Brocker, C., N. Lassen, T. Estey, A. Pappa, M. Cantore, V. V. Orlova, T. Chavakis, K. L. Kavanagh, U. Oppermann, and V. Vasiliou. 2010. Aldehyde dehydrogenase 7A1 (ALDH7A1) is a novel enzyme involved in cellular defense against hyperosmotic stress. J. Biol. Chem. 285:18452-18463. https://doi.org/10.1074/jbc. M109.077925.

Chen, J. Q., P. Szodoray, and M. Zeher. 2016. Toll-like receptor pathways in autoimmune diseases. Clin. Rev. Allergy Immunol. 50:117. https://doi.org/10.1007/s12016-015-8473-z.

Chorazy, M., E. Kontny, J. Marcinkiewicz, and W. Maslinski. 2002. Taurine chloramine modulates cytokine production by human peripheral blood mononuclear cells. Amino Acids 23:407-413 https://doi.org/10.1007/s00726-002-0204-0.

Dai, B., J. Zhang, M. Liu, J. Lu, Y. Zhang, Y. Xu, J. Miao, and Y. Yin. 2016. The role of $\mathrm{Ca}^{2+}$ mediated signaling pathways on the effect of taurine against Streptococcus uberis infection. Vet. Microbiol. 192:26-33.

Ekremoğlu, M., N. Turkozkan, H. Erdamar, Y. Kurt, and H. Yaman. 2007. Protective effect of taurine on respiratory burst activity of polymorphonuclear leukocytes in endotoxemia. Amino Acids 32:413-417. https://doi.org/10.1007/s00726-006-0382-2.

Erdamar, H., N. Turkozkan, M. Ekremoğlu, Y. Kurt, and H. Yaman. 2007. The effect of taurine on polymorphonuclear leukocyte functions in endotoxemia. Amino Acids 33:581-585. https://doi. org/10.1007/s00726-007-0543-y.
Finkelstein, J. D. 1990. Methionine metabolism in mammals. J. Nutr. Biochem. 1:228-237.

Futosi, K., S. Fodor, and A. Mocsai. 2013. Neutrophil cell surface receptors and their intracellular signal transduction pathways. Int. Immunopharmacol. 17:638-650. https://doi.org/10.1016/j. intimp.2013.06.034.

Garcia, M., T. H. Elsasser, L. Juengst, Y. Qu, B. J. Bequette, and K. M. Moyes. 2016. Short communication: Amino acid supplementation and stage of lactation alter apparent utilization of nutrients by blood neutrophils from lactating dairy cows in vitro. J. Dairy Sci. 99:3777-3783. https://doi.org/10.3168/jds.2015-10086.

Gruse, J., E. Kanitz, J. M. Weitzel, A. Tuchscherer, T. Stefaniak, P. Jawor, S. Wolffram, and H. M. Hammon. 2016. Quercetin feeding in newborn dairy calves cannot compensate colostrum deprivation: Study on metabolic, antioxidative and inflammatory traits. PLoS One 11:e0146932. https://doi.org/10.1371/journal.pone.0146932.

Hampton, M. B., A. J. Kettle, and C. C. Winterbourn. 1998. Inside the neutrophil phagosome: Oxidants, myeloperoxidase, and bacterial killing. Blood 92:3007-3017.

Hill, T. M., H. G. Bateman 2nd, J. M. Aldrich, R. L. Schlotterbeck, and K. G. Tanan. 2008. Optimal concentrations of lysine, methionine, and threonine in milk replacers for calves less than five weeks of age. J. Dairy Sci. 91:2433-2442. https://doi.org/10.3168/ jds.2007-0610.

Hulbert, L. E., and S. J. Moisa. 2016. Stress, immunity, and the management of calves. J. Dairy Sci. 99:3199-3216. https://doi org $/ 10.3168 /$ jds.2015-10198.

Jacometo, C. B., J. S. Osorio, M. Socha, M. N. Correa, F. PiccioliCappelli, E. Trevisi, and J. J. Loor. 2015. Maternal consumption of organic trace minerals alters calf systemic and neutrophil mRNA and microRNA indicators of inflammation and oxidative stress. J. Dairy Sci. 98:7717-7729. https://doi.org/10.3168/jds.2015-9359.

Kim, R. D. M., Y.-L. Yin, and G. Wu. 2007. Functional amino acids and fatty acids for enhancing production performance of sows and piglets. Asian-australas. J. Anim. Sci. 20:295-306. https://doi. org/10.5713/ajas.2007.295.

Kobayashi, S. D., and F. R. DeLeo. 2009. Role of neutrophils in innate immunity: A systems biology-level approach. Wiley Interdiscip. Rev. Syst. Biol. Med. 1:309-333. https://doi.org/10.1002/ wsbm.32.

Ley, K. 2003. The role of selectins in inflammation and disease. Trends Mol. Med. 9:263-268. https://doi.org/10.1016/S14714914(03)00071-6.

Li, C., F. Batistel, J. S. Osorio, J. K. Drackley, D. Luchini, and J. J. Loor. 2016. Peripartal rumen-protected methionine supplementation to higher energy diets elicits positive effects on blood neutrophil gene networks, performance and liver lipid content in dairy cows. J. Anim. Sci. Biotechnol. 7:18. https://doi.org/10.1186/ s40104-016-0077-9.

Li, P., Y. L. Yin, D. Li, S. W. Kim, and G. Wu. 2007. Amino acids and immune function. Br. J. Nutr. 98:237-252. https://doi org/10.1017/S000711450769936X.

Marcinkiewicz, J., A. Grabowska, J. Bereta, K. Bryniarski, and B. Nowak. 1998. Taurine chloramine down-regulates the generation of murine neutrophil inflammatory mediators. Immunopharmacology 40:27-38.

McKeever, M. P., D. G. Weir, A. Molloy, and J. M. Scott. 1991. Betaine-homocysteine methyltransferase: Organ distribution in man, pig and rat and subcellular distribution in the rat. Clin. Sci. (Lond.) 81:551-556.

Miao, J., J. Zhang, L. Zheng, X. Yu, W. Zhu, and S. Zou. 2012. Taurine attenuates Streptococcus uberis-induced mastitis in rats by increasing T regulatory cells. Amino Acids 42:2417-2428. https:// doi.org/10.1007/s00726-011-1047-3.

Nordberg, J., and E. S. Arner. 2001. Reactive oxygen species, antioxidants, and the mammalian thioredoxin system. Free Radic. Biol Med. 31:1287-1312.

NRC. 2001. Nutrient Requirements of Dairy Cattle. 7th ed. Natl Acad. Press, Washington, DC.

Osorio, J. S., P. Ji, J. K. Drackley, D. Luchini, and J. J. Loor. 2013. Supplemental Smartamine M or MetaSmart during the transition 
period benefits postpartal cow performance and blood neutrophil function. J. Dairy Sci. 96:6248-6263. https://doi.org/10.3168/ jds.2012-5790.

Osorio, J. S., P. Ji, J. K. Drackley, D. Luchini, and J. J. Loor. 2014a. Smartamine M and MetaSmart supplementation during the peripartal period alter hepatic expression of gene networks in 1-carbon metabolism, inflammation, oxidative stress, and the growth hormone-insulin-like growth factor 1 axis pathways. J. Dairy Sci. 97:7451-7464. https://doi.org/10.3168/jds.2014-8680.

Osorio, J. S., E. Trevisi, P. Ji, J. K. Drackley, D. Luchini, G. Bertoni, and J. J. Loor. 2014b. Biomarkers of inflammation, metabolism, and oxidative stress in blood, liver, and milk reveal a better immunometabolic status in peripartal cows supplemented with Smartamine M or MetaSmart. J. Dairy Sci. 97:7437-7450. https://doi. org $/ 10.3168 /$ jds.2013-7679.

Paape, M. J., D. D. Bannerman, X. Zhao, and J. W. Lee. 2003. The bovine neutrophil: Structure and function in blood and milk. Vet. Res. 34:597-627. https://doi.org/10.1051/vetres:2003024.

Pahl, H. L. 1999. Activators and target genes of Rel/NF-kappa B transcription factors. Oncogene 18:6853-6866. https://doi. org/10.1038/sj.onc.1203239

Schalinske, K. L. 2008. Hepatic sulfur amino acid metabolism. Pages 73-90 in Glutathione and Sulfur Amino Acids in Human Health and Disease. John Wiley \& Sons Inc., Hoboken, NJ.

Schuller-Levis, G. B., and E. Park. 2004. Taurine and its chloramine: Modulators of immunity. Neurochem. Res. 29:117-126.

Sordillo, L. M., and V. Mavangira. 2014. The nexus between nutrient metabolism, oxidative stress and inflammation in transition cows. Anim. Prod. Sci. 54:1204-1214. https://doi.org/10.1071/AN14503.

Stevens, E. A., J. D. Mezrich, and C. A. Bradfield. 2009. The aryl hydrocarbon receptor: A perspective on potential roles in the immune system. Immunology 127:299-311. https://doi.org/10.1111/ j.1365-2567.2009.03054.x.

Stockinger, B., K. Hirota, J. Duarte, and M. Veldhoen. 2011. External influences on the immune system via activation of the aryl hydrocarbon receptor. Semin. Immunol. 23:99-105. https://doi. org/10.1016/j.smim.2011.01.008.

Svensson, C., A. Linder, and S. O. Olsson. 2006. Mortality in Swedish dairy calves and replacement heifers. J. Dairy Sci. 89:4769-4777. https://doi.org/10.3168/jds.S0022-0302(06)72526-7.
Tome, M. E., D. B. Johnson, L. M. Rimsza, R. A. Roberts, T. M. Grogan, T. P. Miller, L. W. Oberley, and M. M. Briehl. 2005. A redox signature score identifies diffuse large B-cell lymphoma patients with a poor prognosis. Blood 106:3594-3601. https://doi. org/10.1182/blood-2005-02-0487.

Trevisi, E., N. Jahan, G. Bertoni, A. Ferrari, and A. Minuti. 2015. Pro-inflammatory cytokine profile in dairy cows: Consequences for new lactation. Ital. J. Anim. Sci. 14:3862. https://doi.org/10.4081/ ijas.2015.3862.

Waterland, R. A. 2006. Assessing the effects of high methionine intake on DNA methylation. J. Nutr. 136:1706S-1710S.

Windeyer, M. C., K. E. Leslie, S. M. Godden, D. C. Hodgins, K. D. Lissemore, and S. J. LeBlanc. 2014. Factors associated with morbidity, mortality, and growth of dairy heifer calves up to 3 months of age. Prev. Vet. Med. 113:231-240. https://doi.org/10.1016/j. prevetmed.2013.10.019.

Wolowczuk, I., C. Verwaerde, O. Viltart, A. Delanoye, M. Delacre, B. Pot, and C. Grangette. 2008. Feeding our immune system: Impact on metabolism. Clin. Dev. Immunol. 2008:639803. https://doi org $/ 10.1155 / 2008 / 639803$.

Wright, C. E., H. H. Tallan, Y. Y. Lin, and G. E. Gaull. 1986. Taurine: Biological update. Annu. Rev. Biochem. 55:427-453. https://doi. org/10.1146/annurev.bi.55.070186.002235.

Wu, G. 2009. Amino acids: Metabolism, functions, and nutrition. Amino Acids 37:1-17. https://doi.org/10.1007/s00726-009-0269-0.

Zhou, Z., O. Bulgari, M. Vailati-Riboni, E. Trevisi, M. A. Ballou, F. C Cardoso, D. N. Luchini, and J. J. Loor. 2016a. Rumen-protected methionine compared with rumen-protected choline improves immunometabolic status in dairy cows during the peripartal period. J. Dairy Sci. 99:8956-8969. https://doi.org/10.3168/jds.201610986.

Zhou, Z., M. Vailati-Riboni, E. Trevisi, J. K. Drackley, D. N. Luchini, and J. J. Loor. 2016b. Better postpartal performance in dairy cows supplemented with rumen-protected methionine compared with choline during the peripartal period. J. Dairy Sci. 99:8716-8732. https://doi.org/10.3168/jds.2015-10525. 